\title{
Common Hazards to Consider During Manufacturing of Feed for Beef and Dairy Cattle ${ }^{1}$
}

\author{
Taylor Langford, Matthew Hersom, Luiz Ferraretto, Antonio Faciola, Chad Carr, and Jason \\ Scheffler ${ }^{2}$
}

\section{Introduction}

The Food Safety Modernization Act (FSMA) was signed into law in January of 2011. FSMA attempts to shift the focus of food safety from reacting to foodborne outbreaks to preventing them from occurring. The law stipulates that complying facilities that manufacture, process, pack, or hold food (hereafter referred to as feed) or feed ingredients for animals must implement Hazard Analysis and Risk-Based Preventive Controls, or HARPC (FDA 2017c; Scheffler and Carr 2016). HARPC has similarities to the Hazard Analysis and Critical Control Points (HACCP) that are commonly used in foods for humans, such as meat, seafood, and juice, but may be unfamiliar to facilities producing feed for livestock. For more information on compliance requirements and the general structure of an animal food safety plan, consult EDIS document AN330, The Food Safety Modernization Act (FSMA) Preventive Controls for Animal Food (http://edis.ifas.ufl.edu/an330).

The first step in writing a food safety plan is to conduct a hazard analysis. Hazards are divided into biological, chemical (including radiological), or physical categories that are known to be, or have the potential to be, associated with the facility or the animal food. A thorough hazard analysis should identify potential hazards as well as their frequency and severity in order to determine the methods for prevention. In many cases, a facility's compliance with written Current Good Manufacturing Practices (CGMPs) and Standard Operating Procedures (SOPs) can prevent hazards. However, some hazards require more robust preventive controls. The determination of whether a hazard requires a preventive control depends on the hazard's frequency and severity, which vary based on the facility and species being fed. This document provides a list of common hazards to consider in the manufacturing of cattle feeds. This is not a comprehensive list. A thorough hazard analysis performed by a preventive controls qualified individual (PCQI) is required to identify hazards for each facility. For more information about PCQIs, visit http://edis.ifas.ufl. edu/an330.

\section{Why is it important to prevent hazards from occurring in animal feed?}

The Federal Food, Drug, and Cosmetic Act requires that "all animal food, including human food, be safe to eat, produced under sanitary conditions, contain no harmful substances, and be truthfully labeled" (FDA 2016). The animal and pet food industry is a multibillion-dollar industry that experiences recalls every year due to food safety hazards. The average cost of a recall to a food company is $\$ 10$ million and includes losses directly associated with the affected food as well as lost sales and brand damage

1. This document is AN343, one of a series of the Department of Animal Sciences, UF/IFAS Extension. Original publication date March 2018. Visit the EDIS website at http://edis.ifas.ufl.edu.

2. Taylor Langford, graduate student; Matthew Hersom, associate professor; Luiz Ferraretto, assistant professor; Antonio Faciola, assistant professor; Chad Carr, associate professor; and Jason Scheffler, assistant professor, Department of Animal Sciences; UF/IFAS Extension, Gainesville, FL 32611. 
(Grocery Manufacturers Association 2010). In some cases, the recall may be such a financial burden that companies cannot recover from it. However, the implication of food safety hazards goes beyond economics. Food safety hazards in animal feed can also cause risks to humans. For example, aflatoxins can be consumed by dairy cattle, released into the milk, and cause damage to the urinary, digestive, nervous, and reproductive systems in humans (Mukherjee 2012).

\section{What are the common physical hazards to consider?}

Physical hazards include stones, glass, metal, wood, plastic, or any physical object that could enter the feed and cause harm. The process of harvesting and processing cattle feed requires machinery, equipment, and processes that can unintentionally introduce physical hazards. Broken parts and shards of metal could be mixed into feed ingredients. A poorly located and unprotected light bulb has a risk of shattering. Tools, cell phones, glasses and other objects may be misplaced or fall into processing equipment and become physical hazards in the feed.

The frequency and severity of a physical hazard depend on each facility and process. A facility might choose to utilize a magnet or a screen to remove contaminants as part of their SOPs to reduce the frequency of the hazard. In addition, shatterproof bulbs can be strategically located to reduce the risk of glass contamination. Standard Operating Procedures for handling tools and personal effects can mitigate risk of those objects becoming physical hazards. Each facility should take into account the source of ingredients, product flow, equipment, storage, and packaging to determine the points where physical hazards could enter the product as well as the appropriate measures to prevent them.

\section{What are the common biological hazards to consider?}

The biological hazards of concern in cattle feed are relatively few in comparison to those in human and pet food. Cattle are more resilient to biological hazards than humans due to the huge population of microorganisms in the rumen that can detoxify some hazards. In addition, cattle feed often comes in less direct contact with humans than pet food and poses less of a risk to human health.

Salmonella is the most likely biological hazard that is targeted for prevention in cattle feed because it poses the most significant risk to human and animal health. Although humans are susceptible to a wide range of Salmonella enterica serotypes, the serotypes of concern in dairy and beef cattle feed are Salmonella Newport and Salmonella Dublin (FDA 2009). However, the incidence of those serotypes is low in cattle feed (Li et al. 2012). Some studies have shown that Salmonella Typhimurium poses a risk to cattle, with higher fatality rates in calves (McGuirk and Peek 2003). However, only a $5.4 \%$ incidence rate of Salmonella Typhimurium was detected in cattle feed (Li et al. 2012). While these studies suggest that the risk for disease in humans and animals caused by Salmonella is relatively low, each facility should perform a risk assessment to determine the likelihood and severity of an outbreak.

Bovine spongiform encephalopathy (BSE) is a neurological disease that can be transmitted through the nervous tissues of ruminants to other animals. In 1997, the FDA prohibited the use of most mammalian protein in the manufacture of feed given to ruminant animals to prevent the transmission of BSE through animal feed (FDA 2012). Due to regulations prohibiting the feeding of ruminant tissues to ruminants, as well as intense efforts to eradicate BSE, a BSE outbreak is unlikely to occur. As a result of those efforts, the United States is classified as a "Negligible Risk Country" (World Organisation for Animal Health 2017).

\section{What are the common chemical hazards?}

The list of chemical hazards affecting cattle feed is longer and more complex than the lists of physical and biological hazards. In addition, there are differences in the risks associated with beef and dairy cattle. For example, due to the high risk for aflatoxins, the FDA has set a default action level for Aflatoxins in Animal Feeds at 20 parts per billion (ppb) (FDA 2015a). However, exceptions have been added for finishing cattle (300 ppb) and breeding beef cattle (100 $\mathrm{ppb}$ ) because of a reduced risk to the animal and to humans consuming products derived from those animals (meat versus milk (Table 1)). The risks of chemical hazards are unique to each facility. Chemical hazards in animal feed can be broken down into three categories: naturally occurring, unintentionally introduced, and intentionally introduced. While not a comprehensive review of all the chemical hazards that may occur, this section highlights the major chemical hazards associated with cattle feeds. It is important to recognize that chemical hazards that could affect animal feeds vary widely and must be detected through a thorough hazard analysis. 


\section{Naturally Occurring}

Mycotoxins are the most common naturally occurring chemical hazard in beef and dairy cattle feed. Although mold is considered a biological system, the mycotoxins produced by certain types of mold are classified as chemical hazards. There are several different kinds of mycotoxins, and their severity depends on the concentration and the animal consuming the mycotoxin. The most common mycotoxins are aflatoxin $\mathrm{B} 1$, fumonisin $\mathrm{B} 1$, zearalenone, ochratoxin, vomitoxin, T-2, and HT-2.

Aflatoxins are mycotoxins that cause the most concern because of their frequency and severity. Aflatoxins can cause severe problems to human health and different levels of illness in animals. They are particularly troubling because they can be transmitted from animal feed to milk, meat, and eggs. In addition, very low levels of aflatoxins are enough to exceed the FDA action level (20 ppb) in food for human consumption. Aflatoxins are poisonous by-products of the mold fungus Aspergillus flavus, Aspergillus parasiticus, and Aspergillus nomius, which are found in crops used as feed ingredients for livestock, such as corn, peanut, and cottonseed. Exercise caution when handling any feed grown under tropical and subtropical conditions that has not been dried or processed immediately after harvesting (FAO and IFIF 2010). Dry and hot climates make corn prone to aflatoxin contamination (Medina, Rodriguez, and Magan 2014). Furthermore, insect and rodent infestation may facilitate mold proliferation in stored feedstuffs. Thus, the frequency of Aspergillus contamination is usually dependent upon weather conditions. Close attention should be paid to the source of corn and corn by-products. Monitoring the weather in the region where feedstuffs are being sourced can help determine the likelihood of aflatoxin contamination and the needed measures to prevent contamination.

The addition of certain clay-based sequestering agents to dairy cattle diets has successfully reduced gastrointestinal availability of aflatoxins and their transfer into milk. Consideration of feed additives that have research-based protective effects in areas of aflatoxin prevalence is advised.

Anti-nutrients are common substances found in animal feed and water. These substances (e.g., gossypol, glucosinolates, erucic acids, and alkaloids) may reduce the availability of nutrients, impair animal production and reproduction, and compromise animal immune systems. Caution is advised when using new alternative feed ingredients or industrial by-products that may contain high levels of anti-nutrients.
Undeclared allergens are the leading cause of recalls in human food (FDA 2016b). However, allergens are not considered a serious hazard in animal feed. Generally, allergies may manifest themselves as dermatitis in animals rather than the severe allergic reactions observed in humans. No serious adverse effects of allergens in animal food have been reported to the Reportable Food Registry from 2009 to 2014 (FDA 2016b).

\section{Unintentionally Introduced}

Unintentionally introduced chemical hazards in cattle feed occur at a relatively low frequency, but their effects can be severe. Examples of unintentionally introduced chemical hazards include, but are not limited to, pesticides and other chemical residues, drug carryover, and nutrient deficiencies or toxicities.

Since many crops used as animal feed ingredients are treated with pesticides and other chemicals to ensure acceptable or desired yields, they may contain chemical residues. In addition, the processes of harvesting and manufacturing expose feedstuffs to possible contamination by petroleum-based greases and other chemicals. These residues can pose risks to animals as well as humans due to the accumulation of these products in fat tissues. The FDA Pesticide Monitoring Program suggests that very few animal feeds contain levels of residues that exceed permitted levels (FDA 2012b). More information about pesticide residues in animal feedstuffs can be found in the Compliance Policy Guide Sec. 575.100 Pesticide Residues in Food and Feed (FDA 2017d). The likelihood of introduction of these chemicals to feedstuffs should be determined during a hazard analysis, and appropriate prevention methods should be implemented.

Drug carryover is particularly important in facilities which manufacture or process feed for multiple species. Certain animal species are fatally sensitive to drug residues, which are important components of medicated feeds for other species. Monensin or monensin sodium, sometimes marketed under trade name Rumensin ${ }^{\oplus}$, is a class of ionophore used as a coccidiostat in ruminants. However, horses are extremely sensitive to monensin, and exposure to this ingredient is fatal $(2-3 \mathrm{mg} / \mathrm{kg}$ of body weight result in death). Therefore, facilities that use monensin and produce, pack, or hold feed for both cattle and horses need to take extra precautions.

Cattle producers should understand the impacts that carryovers can have and learn ways to effectively prevent them. The risks associated with drug residues are specific 
to each facility and increased in facilities that produce feeds for multiple species.

All medicated animal feed must be manufactured and distributed with the Current Good Manufacturing Requirements of Medicated Feeds (FDA 2017c). It is important to note that feed additives containing medically important antimicrobials may fall under the Veterinary Feed Directive (VFD). The VFD brings therapeutic uses of drugs under veterinary supervision and requires a prescription to use medically important drugs in feed or water of foodproducing animals. For more information about which feed additives may fall under the VFD, visit the FDA website (FDA 2015c).

Recalls related to nutrient deficiencies and toxicities are less common in cattle feed than in feed for other species, such as cats, dogs, and sheep. In most cases, cattle feeds are not intended to be the sole source of nutrients. They are supplemented with forage, mineral and vitamin mix, etc., which minimize the risks for nutrient deficiencies. Cattle can also tolerate mineral levels that are above their requirements. However, any mineral can be toxic if consumed in sufficient amounts. Mineral toxicities typically manifest themselves in decreased animal performance, but extreme cases can result in chronic problems and death. In addition, many minerals have antagonistic properties and can interfere with normal absorption of other minerals. The mineral contents of by-product ingredients, such as sulfur levels in dried distiller's grains, should also be monitored to prevent mineral toxicities. Mineral toxicities are almost always an issue of mixing or total intake, whereas deficiencies are usually due to low concentrations in forage. The common mineral toxicities in Florida cattle are cadmium, copper, fluorine, lead, magnesium, molybdenum, selenium, and sulfur. The common mineral deficiencies in Florida cattle are selenium, copper, zinc, cobalt, magnesium, manganese, and phosphorus. Facilities producing feed for multiple species should be aware of the possible toxicities affecting each species. For example, copper is an often supplemented mineral in cattle feeds, but it is extremely toxic to sheep at levels as low as $9 \mathrm{mg}$ per pound body weight (Blakley 2016). In addition, Jersey cattle are more susceptible to copper toxicity than Holstein cattle.

\section{Intentionally Introduced}

Intentionally introduced chemical hazards can be any of the aforementioned hazards that are introduced to feedstuffs for economic gain or sabotage. The most well-known example of a chemical hazard intentionally introduced for economic gain is melamine in pet food. Melamine is a nitrogen-rich compound that artificially inflates the crude protein content of a feedstuff upon analysis. Intentionally introduced hazards are difficult to predict and should be considered when reviewing CGMPs and SOPs to reduce the risks.

\section{How do I prevent these hazards from occurring?}

There are multiple ways of preventing hazards from occurring in cattle feed. Appropriate methods of prevention depend on the hazard, its severity, and its likelihood of occurring. Robust CGMPs and SOPs are in practice in most facilities, and many already work to prevent hazards. However, there are some hazards that require more intense methods of prevention due to their severity or frequency.

Some facilities implement preventive controls, or additional actions taken to ensure the prevention of certain hazards, and their required components (FDA 2017b). There are four forms of preventive controls: process controls, sanitation controls, supply-chain or supplier controls, and other controls (FDA 2017a). Process controls are the most prevalent in a livestock feed facility. They may include batching and sequencing procedures and daily reconciliation of specific ingredients, such as monensin and other antibiotics.

The decision to use CGMPs and SOPs or preventive controls to control hazards is dependent on each facility and hazard. It is important to note that decisions regarding methods of prevention require documented and thorough justification. Justification should be based on facility experience, illness data, scientific reports, and FDA resources.

\section{Additional Information}

FDA (key requirements for preventive controls for animal feed): http://www.fda.gov/downloads/Food/GuidanceRegulation/FSMA/UCM461884.pdf

FDA (FSMA; animal feed overview): http://www.fda. gov/AnimalVeterinary/Products/AnimalFoodFeeds/ ucm347941.htm

UF/IFAS Department of Animal Sciences (FSMA): http:// animal.ifas.ufl.edu/FSMA/index.shtml

Food Safety Preventive Controls Alliance (FSPCA): https:// www.ifsh.iit.edu/fspca 
Southern Center for FSMA Training: http://sc.ifas.ufl.edu/

\section{References}

Blakley, B. 2016. "Overview of copper poisoning." Merck Veterinary Manual. Accessed on February 10, 2018. http:// www.merckvetmanual.com/toxicology/copper-poisoning/ overview-of-copper-poisoning

Crawford, G. 2007. "Avoiding mineral toxicity in cattle." University of Minnesota Extension. Accessed on February 8, 2018. http://www.extension.umn.edu/agriculture/beef/ components/docs/avoiding_mineral_toxicity_in_cattle.pdf

FAO and IFIF. 2010. "Section 1: Health hazards associated with animal feed." Good Practices for the Feed IndustryImplementing the Codex Alimentarius Code of Practice on Good Animal Feeding: 1-6. Accessed on February 8, 2018. http://www.fao.org/docrep/012/i1379e/i1379e01.pdf

FDA. 2009. "Guidance for FDA Staff: Compliance Policy Guide [December 2009].” Accessed on February 8, 2018. http://www.fda.gov/downloads/ICECI/ComplianceManuals/CompliancePolicyGuidanceManual/UCM192468.pdf

FDA. 2012. "CFR 589.1000 Subpart B-Listing of Specific Substances Prohibited From Use in Animal Food or Feed." Accessed on February 8, 2018. https://www.accessdata.fda. gov/scripts/cdrh/cfdocs/cfcfr/CFRSearch.cfm?CFRPart=58 9\&showFR=1\&subpartNode=21:6.0.1.1.27.2

FDA. 2015a. "Compliance Policy Guide Sec. 683.100 Action Levels for Aflatoxins in Animal Feeds." Accessed on February 8, 2018. https://www.fda.gov/ICECI/ComplianceManuals/CompliancePolicyGuidanceManual/ucm074703.htm

FDA. 2015b. Pesticide Monitoring Program: Fiscal Year 2015 Pesticide Report. Accessed on February 8, 2018. https:// www.fda.gov/downloads/Food/FoodborneIllnessContaminants/Pesticides/UCM582721.pdf

FDA. 2015c. "Veterinary Feed Directive; Final Rule." Federal Register 80(106): 31708-31735. Accessed on February 8, 2018. https://www.gpo.gov/fdsys/pkg/FR-2015-06-03/ pdf/2015-13393.pdf

FDA. 2016a. "Pet food." Accessed on February 8, 2018. https://www.fda.gov/AnimalVeterinary/Products/AnimalFoodFeeds/PetFood/default.htm

FDA. 2016b. "The Reportable Food Registry: A five year overview of targeting inspection resources and identifying patterns of adulteration." U.S. Food and Drug
Administration. Accessed on February 8, 2018. http://www. fda.gov/downloads/Food/ComplianceEnforcement/RFR/ UCM502117.pdf

FDA. 2017a. "21 CFR 507.34 Preventive controls." Accessed on February 8, 2018. https://www.accessdata.fda.gov/ scripts/cdrh/cfdocs/cfCFR/CFRSearch.cfm?fr=507.34

FDA. 2017b. "21 CFR 507.42 Hazard Analyis and RiskBased Preventive Controls." Accessed on February 8, 2018. https://www.accessdata.fda.gov/scripts/cdrh/cfdocs/cfCFR/ CFRSearch.cfm?fr $=507.42$

FDA. 2017c. "21 CFR 225 Current Good Manufacturing Practice for medicated feeds." Accessed on February 8, 2018. https://www.accessdata.fda.gov/scripts/cdrh/cfdocs/ cfcfr/CFRSearch.cfm?CFRPart=225\&showFR $=1$

FDA. 2017d. "CPG Sec. 575.100 Pesticide Residues in Food and Feed - Enforcement Criteria." Accessed on February 8, 2018. https://www.fda.gov/iceci/compliancemanuals/ compliancepolicyguidancemanual/ucm123236.htm

Grocery Manufacturers Association. 2010. "Recall execution effectiveness: Collaboration approaches to improving consumer safety and confidence." Accessed on February 8, 2018. https://www.gmaonline.org/downloads/research-andreports/WP_RecallExecution.pdf

Li, X., L. A. Bethune, Y. Jia, R. A. Lovell, T. A. Proescholdt, S. A. Benz, T. C. Schell, G. Kaplan, and D. G. McChesney. 2012. "Surveillance of Salmonella prevalence in animal feeds and characterization of the Salmonella isolates by serotyping and antimicrobial susceptibility." Foodborne Pathogens and Disease 9(8): 692-698. https://doi. org/10.1089/fpd.2011.1083

McGuirk, S. M. and S. Peek. 2003. "Salmonellosis in cattle: A review." Preconvention Seminar 7: Dairy Herd Problem Investigation Strategies American Association of Bovine Practitioners: 1-10.

Medina, A., A. Rodriguez, and N. Magan. 2014. "Effect of climate change on Aspergillus flavus and aflatoxin B1 production." Frontiers in Microbiology 5: 1-7. https://doi. org/10.3389/fmicb.2014.00348

Mukherjee, S. 2012. "Aflatoxin effect on health." Accessed on February 8, 2018. http://www.fao.org/fileadmin/ user_upload/wa_workshop/ECAfrica-caadp/4._Aflatoxin_USAID.pdf 
Scheffler, J. and C. Carr. 2016. The Food Safety Modernization Act (FSMA) Preventive Controls for Animal Food.

AN330. Gainesville: University of Florida Institute of Food and Agricultural Sciences. http://edis.ifas.ufl.edu/an330

World Organisation for Animal Health. 2017. "List of bovine spongiform encephalopathy risk status of member countries." Accesed on February 8, 2018. http://www.oie. int/en/animal-health-in-the-world/official-disease-status/ bse/list-of-bse-risk-status/

Table 1. FDA action limits for aflatoxins in cattle feeds.

\begin{tabular}{|c|c|c|}
\hline Level & Ingredient & Animal \\
\hline 300 ppb & Corn, cottonseed meal, or peanut products & Finishing beef cattle \\
\hline 100 ppb & $\begin{array}{l}\text { Corn, peanut products, cottonseed meal, other animal } \\
\text { feeds }\end{array}$ & Breeding beef cattle \\
\hline $20 \mathrm{ppb}$ & $\begin{array}{l}\text { Corn, peanut products, other animal feeds, total mixed } \\
\text { rations (dairy cattle) }\end{array}$ & $\begin{array}{l}\text { Immature animals and others not listed (lactating } \\
\text { cattle) }\end{array}$ \\
\hline
\end{tabular}

